\title{
Conscious sedation with inhaled $50 \%$ nitrous oxide/oxygen premix in photodynamic therapy sessions for vulvar lichen sclerosus treatment
}

Joana Cabete ${ }^{1}$

Sara Campos ${ }^{1}$

Sara Lestre ${ }^{1}$

DOI: http://dx.doi.org/10.1590/abd1806-4841.20153112

\begin{abstract}
Photodynamic therapy has been described as an effective therapeutic option in selected cases of anogenital lichen sclerosus that are refractory to first-line treatments. However, procedure-related pain is a limiting factor in patient adherence to treatment. The authors report the case of a 75-year-old woman with highly symptomatic vulvar lichen sclerosus, successfully treated with photodynamic therapy. An inhaled $50 \%$ nitrous oxide/oxygen premix was administered during sessions, producing a pain-relieving, anxiolytic, and sedative effect without loss of consciousness. This ready-to-use gas mixture may be a well-tolerated and accepted alternative to classical anesthetics in Photodynamic therapy, facilitating patients' adherence to illumination of painprone areas.
\end{abstract}

Keywords: Conscious sedation; Photochemotherapy; Vulvar lichen sclerosus

\section{INTRODUCTION}

Lichen sclerosus (LS) is a chronic, autoimmune, inflammatory skin disease of uncertain aetiology. Vulvar LS is associated with severe discomfort and morbidity. Several treatment modalities have been proposed, with the most available evidence for potent topical corticosteroids. When unresponsive to medical therapies, photodynamic therapy (PDT) has been described as a potential alternative, demonstrating symptomatic benefit in small series studies and case reports. ${ }^{1}$ However, pain is still a major limitation to this technique and an important cause of treatment discontinuation.

\begin{abstract}
CASE REPORT
A 75-year-old woman presented with a 15-year history of vulvar lichen sclerosus. She was highly symptomatic, reporting a persistent burning sensation, pain, and pruritus worsened during micturition. Physical examination showed a shiny, ivory, smoothsurfaced plaque surrounding the vulva, with important atrophy causing labial and clitoral resorption, in addition to narrowing of the introitus. Histopathology confirmed the diagnosis of LS. Treatment with clobetasol propionate $0.05 \%$ ointment and amitriptylin 10 $\mathrm{mg}$ /day for 7 months produced little symptomatic relief. Photodynamic therapy using methyl aminolevulinate (MAL) was then instituted. MAL cream was applied to the entire labia, with an occlusive dressing for three hours, followed by illumination with red
\end{abstract}

Approved by the Advisory Board and accepted for publication on 21.10.2013.

* Work performed at the Department of Dermatology, Hospital de Santo António dos Capuchos - Centro Hospitalar de Lisboa Central - Lisboa, Portugal. Financial Support: none

Conflict of Interests: none

Hospital de Santo António dos Capuchos - Centro Hospitalar de Lisboa Central - Lisbon, Portugal. 
light, 630nm wavelength at a light dose of $37 \mathrm{~J} / \mathrm{cm}^{2}$ for 8 minutes and 20 seconds, at a distance of $8 \mathrm{~cm}$ between the device and the lesion surface. An inhaled $50 \%$ nitrous oxide/oxygen premix was administered using a face mask, yielding conscious sedation and pain relief during the entire treatment (Figure 1). Gas flow was controlled by a sensitive demand-valve activated by the patient's inspired breath. Three minutes after the beginning of gas inhalation, PDT was initiated, subject to preliminary moderate sedation (in accordance with the Winsconsin Sedation Scale). Blood pressure, heart rate, oxygen peripheral saturation and sedation score were monitored throughout the procedure. Sedation was reversed using oxygen therapy at a flow rate of 5 litres per minute for $5 \mathrm{~min}$ utes. A total of four PDT sessions were performed. Treatment between sessions included daily amitriptylin and emollient. A visual analogue scale was used to evaluate response to treatment, through a daily record of the intensity of symptoms (from 0 to 10), including dysuria, pain and pruritus.

Patient compliance during PDT treatments under conscious sedation was total, with tolerance to pain, no need for local anaesthesia, and no side effects to report. Symptomatic relief was reported as early as one week after the first treatment. Complete and persistent remission of dysuria has been observed ever since. Pain and pruritus diminished by up to $80 \%$ from baseline after the first two treatments, recurring 10 and 9 weeks later, respectively. However, a longlasting response was experienced after the third session, with absent to mild pain or pruritus during nine months, before recurrence and the need for a fourth treatment (Figure 2). Overall, while clinically unchanged, symptomatic response has been observed following each PDT treatment, with longer intervals between sessions, and great improvement in the patient's quality of life.

\section{DISCUSSION}

Procedure-related pain is a limiting factor in patient adherence to PDT. This adverse event exhibits great interpersonal variation, but is also related to predisposition factors such as location, extent and type of lesion, photosensitizer, fluence, irradiance, and light source. Pain control strategies during PDT have been studied, but none has proved completely effective. For instance, topical anesthetics have proved ineffective in controlling pain during PDT. In addition, injectable anesthetics, though useful, are associated with considerable pain when infiltrated in extensive and pain-prone areas, and lack anxiolytic effect. $^{2}$

When inhaled, a ready-to-use medical gas mixture consisting of $50 \%$ nitrous oxide and $50 \%$ oxygen

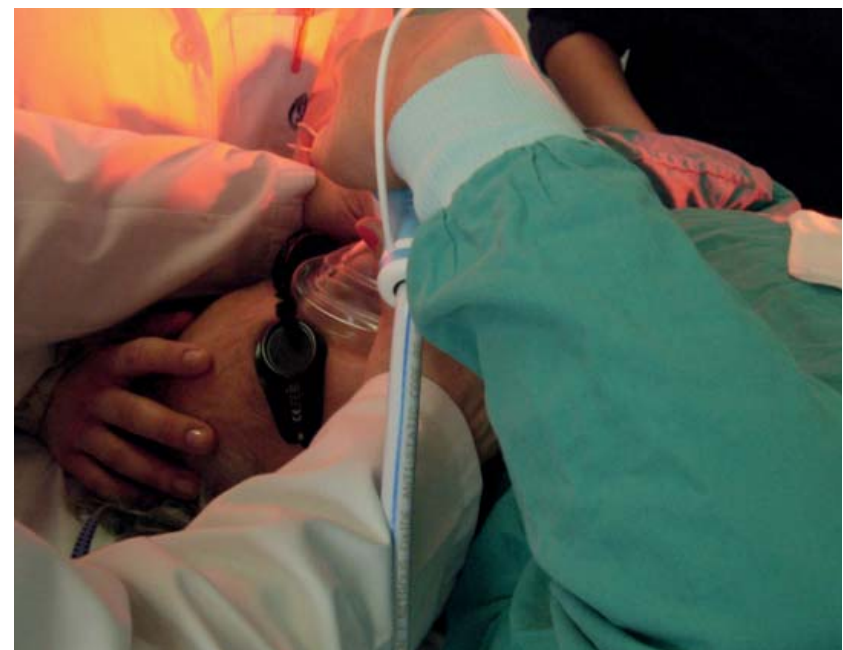

FIGURE 1: Conscious sedation with inhaled 50\% nitrous oxide/ oxygen premix during PDT session

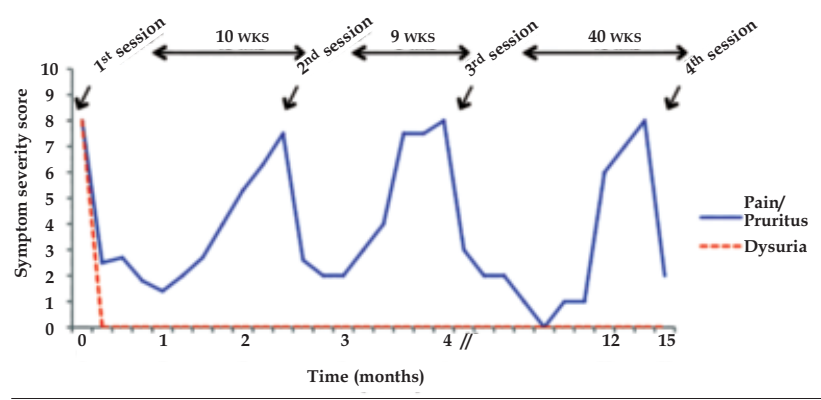

FIGURE 2: Dysuria, pain, and pruritus severity score according to the patient's own records over time, and its relation to PDT sessions. wks, weeks

produces a pain-relieving, anxiolytic and sedative effect without loss of consciousness. It is fast-acting, as the first effects are felt shortly after 4-5 inhalations. It is also self-regulated and rapidly eliminated from the body through pulmonary excretion once inhalation stops, allowing for a quick recovery. This gas premix has proved safe with minimal, reversible side effects that include drowsiness, euphoria and nausea. ${ }^{3}$ It has been widely used over the past decades in short-term procedures where analgesia and sedation with rapid onset and offset, have been sought. While commonly employed in areas such as dentistry, obstetrics, or pediatrics, its use in dermatology appears to be marginal in the literature. ${ }^{4-7}$ No use in PDT has been reported so far.

To the authors' knowledge, this is the first case reporting the use of inhaled nitrous oxide/oxygen gas mixture during PDT performed in the genital area. In the case described, the extension and localization of LS would hardly enable a non-traumatic perineum 
illumination, as this is a well-recognized pain-prone area. Pain control through the use of this gas mixture facilitated patient adherence to PDT, with no need for treatment interruptions, and acceptance of subsequent sessions.

\section{REFERENCES}

1. Neill SM, Lewis FM, Tatnall FM, Cox NH; British Association of Dermatologists. Guidelines for the management of lichen sclerosus 2010. Br J Dermatol. 2010;163:672-82.

2. Chaves YN, Torezan LA, Niwa AB, Sanches Junior JA, Festa Neto C. Pain in photodynamic therapy: mechanism of action and management strategies. An Bras Dermatol. 2012;87:521-6.

3. Onody P, Gil P, Hennequin M. Safety of inhalation of a $50 \%$ nitrous oxide/oxygen premix: a prospective survey of 35828 administrations. Drug Saf. 2006;29:633-40.

4. Sadick NS, Militana CJ. Use of nitrous oxide in hair transplantation surgery. J Dermatol Surg Oncol. 1994;20:186-90.

5. Otley CC, Nguyen TH. Conscious sedation of pediatric patients with combination oral benzodiazepines and inhaled nitrous oxide. Dermatol Surg. 2000;26:1041-4.

6. Claeys A, Gaudy-Marqueste C, Pauly V, Pelletier F, Truchetet F, Boye T, et al. Management of pain associated with debridement of leg ulcers: a randomized, multicentre, pilot study comparing nitrous oxide-oxygen mixture inhalation and lidocaine-prilocaine cream. J Eur Acad Dermatol Venereol. 2011;25:138-44.

7. Drosner M. Nitrous oxide - oxygen analgesia in aesthetic dermatology. Hautarzt. 2013;64:435-42.
In conclusion, the use of a $50 \%$ nitrous oxide/oxygen gas premix may be an economic, safe, well-tolerated and accepted alternative to classical anesthetics in PDT. Easily administered by a trained doctor or nurse, either in inpatient or outpatient settings, it is an attractive, potential adjuvant for numerous, painful dermatological procedures.

\author{
MAILING ADDRESS: \\ Joana Maria Fazenda Cabete \\ Alameda Santo António dos Capuchos \\ 1169-050 Lisbon, Portugal. \\ E-mail: joanacabete@gmail.com
}

How to cite this article: Cabete J, Campos S, Lestre S. Conscious sedation with inhaled 50\% nitrous oxide/oxygen premix in photodynamic therapy sessions for vulvar lichen sclerosus treatment. An Bras Dermatol. 2015;90(1):120-2. 